\title{
Multitarget drugs: an epigenetic epiphany
}

\section{A. Ganesan*[a]}

Abstract: Epigenetics refers to changes in a biological phenotype that are not due to an underlying change in genotype. In eukaryotes, epigenetics involves a set of chemical modifications of the DNA and the histone proteins in nucleosomes. These dynamic changes are carried out by enzymes and modulate protein-protein and proteinnucleic acid interactions to determine whether specific genes are expressed or silenced. Both the epigenetic enzymes and recognition domains are currently important drug discovery targets, particularly for the treatment of cancer. This review summarizes the progress of epigenetic targets that have reached a clinical stage i.e. DNA methyltransferases, histone deacetylases, lysine methyltransferases, lysine demethylases and bromodomains, followed by a comprehensive survey of multitarget drugs that have included an epigenetic target as one of their mechanisms of action.

\section{Introduction}

Genetics is broadly defined as the study of genes and their heredity. At the molecular level, genetics involves the organism's DNA sequence or genome and how it influences the biological phenotype. Genetics has a profound influence on medicinal chemistry as mutations in single or multiple genes are directly linked to or affect the susceptibility to thousands of human diseases. The newer science of epigenetics is concerned not with the actual genes but how their expression is regulated. ${ }^{1}$ In eukaryotic organisms, this involves an elaborate pattern of structural modification of the DNA and histone proteins that constitute the nucleosome. These alterations are introduced by a set of enzymes (called 'writers') and then serve as recognition elements for specific protein-protein and protein-nucleic acid interaction domains (the 'readers'). Meanwhile, a separate set of enzymes (the 'erasers') reverses the action of the writers. Together, the three families of epigenetic players serve to coordinate the complex transcription machinery in eukaryotes and determine if a specific gene is expressed or silenced. Since dysfunctional gene regulation lies at the heart of most human ailments, the modulation of epigenetic processes holds much promise as a new strategy for drug discovery. ${ }^{2}$ Over the last two decades, small molecules with high affinity and selectivity for epigenetic writers, readers and erasers have been identified. These efforts have culminated in numerous clinical candidates and seven approved anticancer agents (Table 1).

Table 1. Approved epigenetic drugs and examples of compounds in clinical development. The marketer or developer is given in brackets. Abbreviations: BRD: bromodomain; DNMT: DNA methyltransferase; HDAC: histone deacetylase; KDM: Iysine demethylase; KMT: Iysine methyltransferase.

[a] Professor A. Ganesan

School of Pharmacy

University of East Anglia

Norwich Research Park, Norwich NR4 7TJ, United Kingdom

E-mail: a.ganesan@uea.ac.uk

\begin{tabular}{|c|c|c|c|}
\hline Compound & Target & Indication & Status \\
\hline $\begin{array}{l}\text { azacitidine } \\
\text { (Celgene) }\end{array}$ & DNMT & $\begin{array}{l}\text { myelodysplastic } \\
\text { syndrome }\end{array}$ & $\begin{array}{l}\text { approved } \\
\text { FDA, } 2004\end{array}$ \\
\hline $\begin{array}{l}\text { decitabine } \\
\text { (Eisai) }\end{array}$ & DNMT & $\begin{array}{l}\text { myelodysplastic } \\
\text { syndrome }\end{array}$ & $\begin{array}{l}\text { approved } \\
\text { FDA, } 2006\end{array}$ \\
\hline $\begin{array}{l}\text { vorinostat } \\
\text { (Merck) }\end{array}$ & HDAC & $\begin{array}{l}\text { cutaneous } \quad T \text { - } \\
\text { cell lymphoma }\end{array}$ & $\begin{array}{l}\text { approved } \\
\text { FDA, } 2006\end{array}$ \\
\hline $\begin{array}{l}\text { romidepsin } \\
\text { (Celgene) }\end{array}$ & HDAC & $\begin{array}{l}\text { cutaneous } \quad T \text { - } \\
\text { cell lymphoma }\end{array}$ & $\begin{array}{l}\text { approved } \\
\text { FDA, } 2009\end{array}$ \\
\hline $\begin{array}{l}\text { belinostat } \\
\text { (Spectrum) }\end{array}$ & HDAC & $\begin{array}{l}\text { peripheral } \quad \mathrm{T} \text { - } \\
\text { cell lymphoma }\end{array}$ & $\begin{array}{l}\text { approved } \\
\text { FDA, } 2014\end{array}$ \\
\hline $\begin{array}{l}\text { panobinostat } \\
\text { (Novartis) }\end{array}$ & HDAC & $\begin{array}{l}\text { multiple } \\
\text { myeloma }\end{array}$ & $\begin{array}{l}\text { approved } \\
\text { FDA, } 2015\end{array}$ \\
\hline $\begin{array}{l}\text { chidamide } \\
\text { (Chipscreen) }\end{array}$ & HDAC & $\begin{array}{l}\text { peripheral } \quad T \text { - } \\
\text { cell lymphoma }\end{array}$ & $\begin{array}{l}\text { approved } \\
\text { CFDA, } 2015\end{array}$ \\
\hline $\begin{array}{l}\text { tazemetostat } \\
\text { (Epizyme) }\end{array}$ & KMT & leukemia & Phase II \\
\hline $\begin{array}{l}\text { ORY-1001 } \\
\text { (Oryzon) }\end{array}$ & KDM & leukemia & Phase I/II \\
\hline $\begin{array}{l}\text { GSK525762 } \\
\text { (GlaxoSmithKline) }\end{array}$ & BRD & $\begin{array}{l}\text { NUT midline } \\
\text { carcinoma }\end{array}$ & Phase I/II \\
\hline
\end{tabular}

Inhibitors of DNA methyltransferases (DNMTs) were the first epigenetic drugs to reach the market. DNMTs catalyze the C- 6 methylation of cytosine residues in CpG dinucleotide sequences within DNA using the methyl donor S-adenosylmethionine (SAM). Cytosine methylation recruits proteins containing methyl binding domains (MBD) with an overall gene silencing effect. While cytosine methylation is concentrated in non-coding regions in normal cells, cancer cells often feature increased methylation at promoters of genes encoding for tumor suppressors or other proteins with an antiproliferative effect. Hence, DNMT inhibitors would reactivate such silenced pathways and have potential utility for anticancer therapy. ${ }^{3}$

The DNMT catalytic cycle begins with addition of the active site cysteine residue to the cytosine base (1, Figure $\mathbf{1})$ which is flipped out of the DNA double helix. This generates an enaminelike intermediate 2 that is methylated by the SAM cofactor. In the final step, $\mathbf{3}$ undergoes elimination to give the 5-methylcytosine product 4 and the regenerated enzyme. In humans, there are two key DNMTs, DNMT1 and DNMT3. DNMT1, the most abundant, is a ubiquitous enzyme responsible for the 
methylation of 'hemi-methylated' DNA to maintain the methylation status of newly synthesized DNA during rounds of replication. DNMT3 is a de novo nethyltransferase that acts upon both non-methylated and hemi-methylated DNA. It establishes CpG methylation patterns during embryogenesis as well as changes to the methylation status in response to the environment. Until recently, it was believed that DNA demethylation was a passive non-enzymatic process. In 2009, the TET (ten-eleven translocation) enzymes were shown to sequentially oxidise 5-methylcytosine residues to 5hydroxymethylcytosine $(5 \mathrm{hmC}), 5$-formylcytosine $(5 \mathrm{fC})$ and 5carboxylcytosine $(5 \mathrm{caC})$ which can then be decarboxylated. ${ }^{4}$

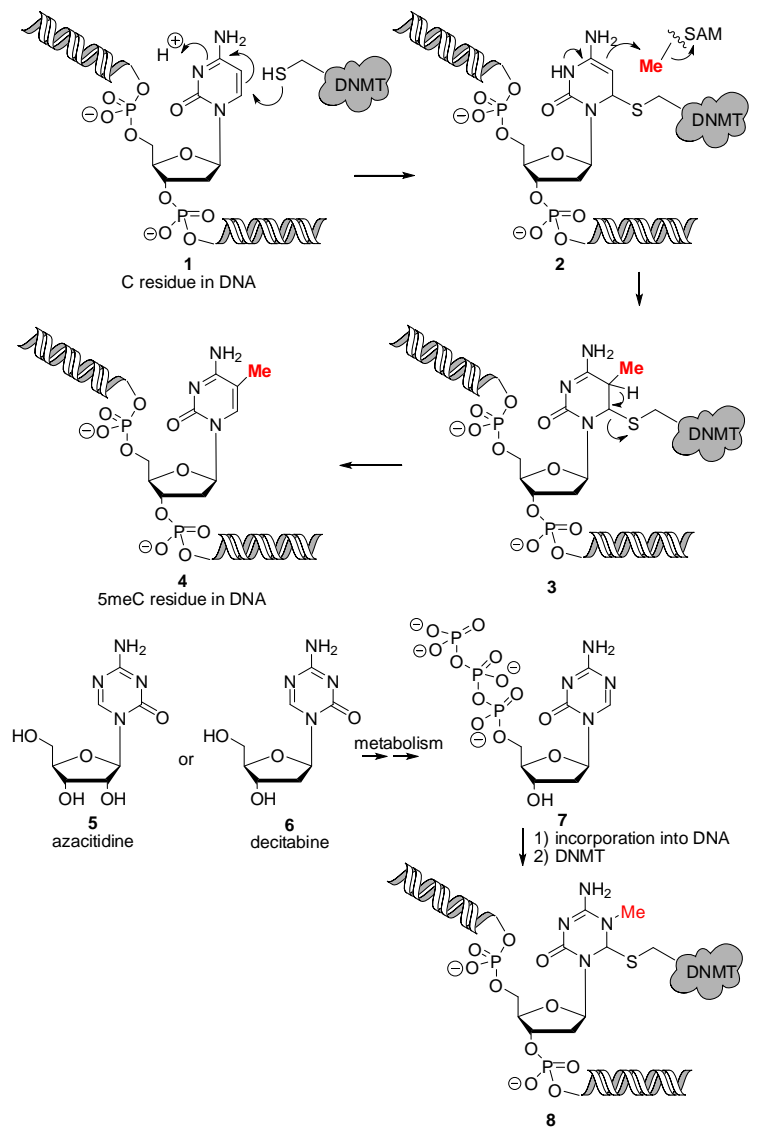

Figure 1. The catalytic cycle of DNA methyltransferases (DNMTs) and the mechanism of enzyme inactivation by the inhibitors azacitidine and decitabine.

The two approved DNMT inhibitors, azacitidine (5) and decitabine (6), are prodrugs that contain a 5-azapyrimidine heterocycle. Both are metabolically transformed to the active species 7 which is incorporated into DNA. The 5-azapyrimidine residue is accepted as a DNMT substrate but does not undergo the final elimination step due to the lack of a C-5 proton. Instead, the enzyme is trapped as the covalent adduct $\mathbf{8}$ and irreversibly inhibited. The two drugs are approved for the treatment of all five stages of myelodysplastic syndrome, a hematopoietic stem cell disorder that often progresses to acute myeloid leukemia (AML). In addition, there are some non-nucleoside DNMT inhibitors at a preclinical stage that work by a different mechanism of action by competing with the SAM cofactor binding pocket.
Moving from DNA to histones, the epigenetic post-translational modification that has received the most attention is lysine acetylation (Figure 2). This is carried out by a large family of histone acetyltransferases (HATs) using acetyl CoA as the cofactor. Although much effort has been expended on the discovery of HAT inhibitors, compounds of high efficacy and selectivity suitable for in vivo studies are yet to be disclosed. ${ }^{5}$ The complementary HAT erasers are the histone deacetylases (HDACs), of which there are eleven human zinc-dependent isoforms. These are subdivided according to sequence homology and cellular localization into Class I (HDAC1, 2, 3 and 8), Class IIa (HDAC4, 5, 7, 9), Class IIb (HDAC6 and 10) and Class IV (HDAC11). ${ }^{6}$ Additionally there are seven sirtuins (Class III, sirtuins 1-7) implicated in energy homeostasis that hydrolyse acetyl-lysine by a different mechanism involving $\mathrm{NAD}^{+}$as the cofactor. ${ }^{7}$ While HDAC inhibitors are a relatively mature drug discovery target with five approvals to date, the inhibition of sirtuins is less advanced and at the preclinical stage.

In histones, lysine acetylation decreases their affinity for DNA and opens up the nucleosome permitting gene transcription to occur. Furthermore, acetylation is a recruitment signal for binding by the bromodomain (see below). By removing histone acetylation, HDACs act as gene repressors in a similar fashion to DNMTs and the value of HDAC inhibitors lies in the reactivation of silenced pathways in cancer cells. Nevertheless, it should be kept in mind that the HAT/HDAC nomenclature is misleading as reversible lysine acetylation is not restricted to histones and occurs in thousands of human proteins. Furthermore, many other acylations occur besides acetylation such as butyrylation, crotonylation, succinylation and biotinylation. ${ }^{8}$ Part of the therapeutic benefit of inhibiting HDACs, or indeed the side effects, may derive from non-epigenetic events rather than modulation of the nucleosome.

All potent inhibitors of the zinc-dependent HDACs have a pharmacophore consisting of three elements. First, there is a metal-binding warhead that reversibly coordinates to the active site zinc cation. Second, there is a spacer that occupies the narrow active site channel and mimics the lysine side-chain of the substrate. Finally, there is a cap that sits on the enzyme surface above the channel and is partially solvent exposed. Vorinostat (9, also known as suberoylanilide hydroxamic acid, SAHA), the first approved HDAC inhibitor, has a hydroxamic acid zinc-binding warhead, a linear spacer and a short phenyl cap and is a panHDAC inhibitor. The second approved HDAC inhibitor romidepsin (10, also known as FK228), is a natural product primarily active against Class I HDACs. It is a prodrug containing a disulfide bridge that is reduced in vivo to release the thiol zinc-binding warhead in $\mathbf{1 1 .}$

The success of vorinostat has spurred many hydroxamic acid fast followers that are typically superior in pharmacokinetics such as panobinostat (12) as well as benzamides exemplified by chidamide (13) which received approval in China in 2014 for the treatment of peripheral T-cell lymphoma. Panobinostat is unique among the clinical HDAC inhibitors as it is approved for refractory or relapsed multiple myeloma rather than the treatment of relatively rare $\mathrm{T}$ cell lymphomas. It is possible that isoform selective HDAC inhibitors will be better tolerated than the currently approved drugs and have a broader spectrum of applications. One example, rocilinostat (14) is in clinical trials and has ten-fold selectivity for HDAC6 over other isoforms. For several isoforms, X-ray crystal structures of protein-inhibitor 
complexes are available and this has facilitated structure-based drug design. ${ }^{9}$
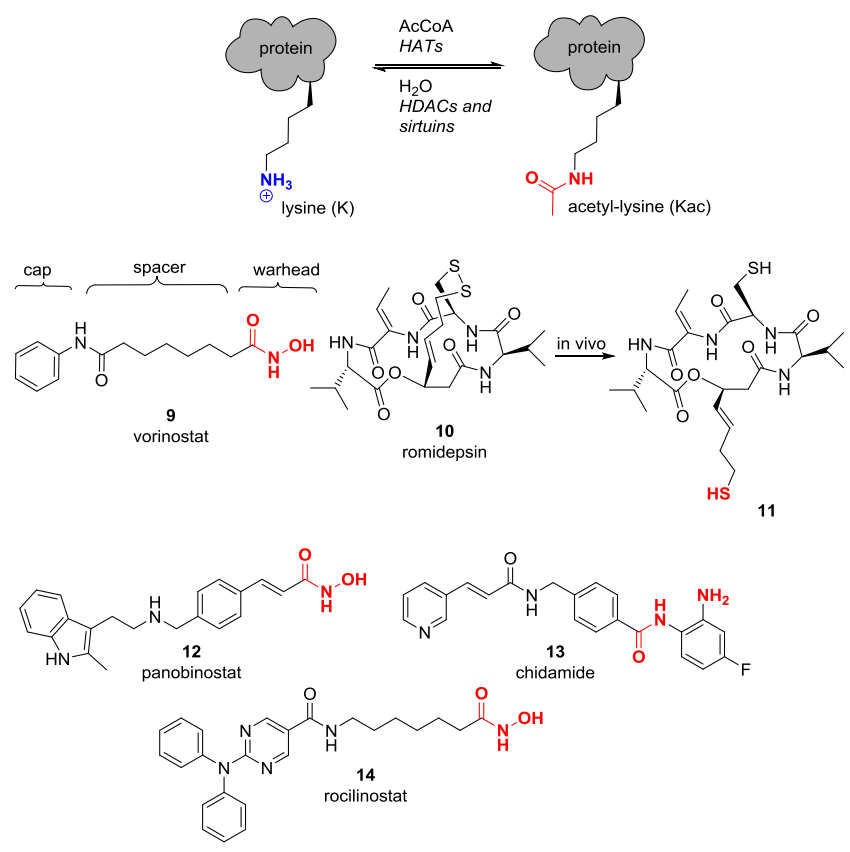

Figure 2. Reversible lysine acetylation and examples of HDAC inhibitors that are approved or in clinical development, with zinc-binding warheads in red.

Three newer epigenetic targets - lysine methyltransferases, lysine demethylases and bromodomains - have recently led to clinical candidates. Lysine methyltransferases (KMTs) are a relatively large family of $\sim 100$ enzymes that use SAM as the cofactor to methylate lysine residues once, twice or three times (Figure 3) while the related arginine methyltransferases (PRMTs) perform methylation at arginine residues. ${ }^{10,11}$ In histones, the consequences of methylation are contextdependent and can lead to either gene activation or repression. The drug discovery strategy for KMT inhibition has involved reversible occupancy of the SAM cofactor binding pocket. Although all KMTs as well as other methyltransferases utilize SAM, there are sufficient differences in their binding pocket for selective inhibition to be achieved, in much the same way that ATP mimetics can be selective for particular kinases. Epizyme's EPZ-5676 (15), the first KMT inhibitor to enter clinical trials, is a picomolar inhibitor of DOT1L with greater than 30,000-fold selectivity against other KMTs while GlaxoSmithKline's GSK2816126 (16) is a selective EZH2 inhibitor in Phase I trials.

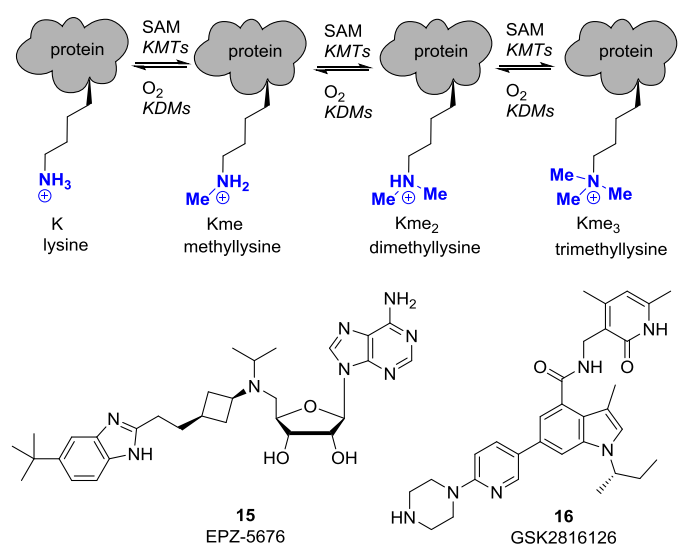

Figure 3. Reversible lysine methylation and two examples of SAM mimetic KMT inhibitors in clinical development.

Lysine demethylases (KDMs) act in opposition to KMTs to erase the methyl marks introduced by the latter. They are subdivided into two families based on the catalytic mechanism: KDM1 comprises the lysine-specific demethylases LSD1 and LSD2, enzymes that use FAD as a cofactor and are homologous to monoamine oxidases (MAOs); KDM2-7, known as the Jumonji (JmjC) demethylases, contain about twenty human members and are part of the 2-oxoglutarate and iron(II)-dependent dioxygenases. The increased expression or activity of both LSD and $\mathrm{JmjC}$ demethylases is implicated in a variety of cancers. Due to the similarity between LSD1 and MAOs, MAO inhibitors were investigated for their ability to inhibit LSD1. The old drug tranylcypromine (17, Figure 4) is a micromolar LSD1 inhibitor, undergoing ring opening to generate a radical intermediate that covalently adds to the FAD cofactor. Tranylcypromine analogues from Oryzon (18) and GlaxoSmithKline (19) with nanomolar potency and high selectivity towards LSD1 over MAOs are currently in clinical trials for leukemia while a combination therapy of tranylcypromine and all-trans retinoic acid is also under investigation. As for the JmjC demethylases, a number of preclinical small molecule inhibitors have been reported that act by chelation of the active site iron cation. ${ }^{12}$

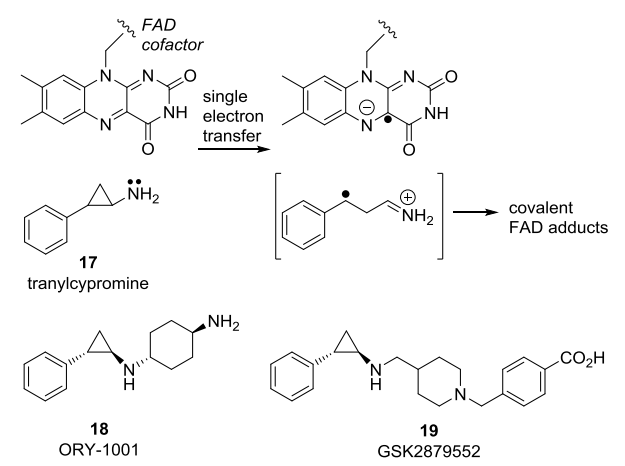

Figure 4. The mechanism of action by which tranylcypromine irreversibly inhibits MAOs and LSD1 and the structures of LSD1 selective tranylcypromine analogues in clinical trials.

The bromodomains (BRDs) are the first epigenetic readers for which ligands have reached clinical validation. These domains of which there are 61 human examples, are approximately 110 
amino acid residues in size and contain a hydrophobic pocket that specifically recognizes acetyl-lysine residues. Among the bromodomains, the BET (bromo and extra terminal) domain comprising BRD2, BRD3, BRD4 and BRDT has attracted the most interest for drug discovery. BRD4 is enriched in enhancer regions and drives the expression of oncogenes in cancers while translocations fusing BRD3 or BRD4 to the NUT oncogene are responsible for NUT midline carcinoma, a cancer with a very poor survival rate. Synthetic ligands selective for the BET domain include the tool compound JQ1 and examples from Resverlogix (20, Figure 5), GlaxoSmithKline (21) and OncoEthix (22) undergoing clinical trials. ${ }^{13}$

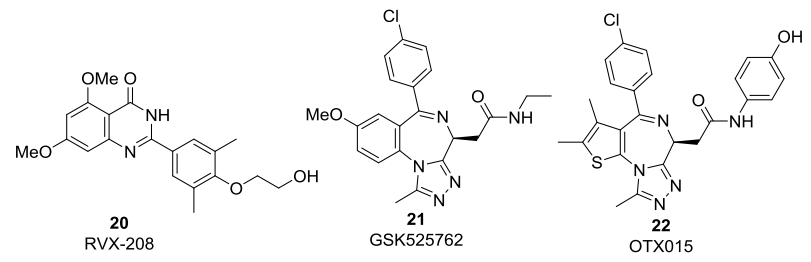

Figure 5. Examples of BET ligands in clinical trials.

Having briefly summarised the major epigenetic targets, we can now evaluate their potential in mulitargeted drugs. The theoretical basis for such an approach lies in the synergy observed between an epigenetic drug and one acting by a separate mechanism of action in cell-based and animal models for cancer and other indications. Some of these combinations are now being tested in clinical trials to provide proof of concept in man. In principle, a multiargeted drug would be an alternative to such a drug cocktail with the potential advantages of targeting two mechanisms through a single agent rather than coadministration of two drugs. Among the epigenetic targets, designing a molecule with such a dual mechanism of action would be most challenging with the DNMT inhibitors $\mathbf{5}$ and $\mathbf{6}$ due to the requirement for a nucleoside with limited scope for further elaboration. At the other extreme, the simple pharmacophore of HDACs is tolerant of a large variety of cap groups. As this region interacts with the enzyme surface, it can be engineered to include a second pharmacophore without drastic loss of HDAC affinity. Many successful examples have been reported including two candidates from Curis in clinical development (see below). The other epigenetic targets lie somewhere in between DNMTs and HDACs in terms of degree of difficulty of scaffold modification to provide multitarget compounds. Earlier examples of such multitarget drugs are covered in a review by de Lera. ${ }^{14}$

\section{Dual HDAC and kinase inhibitors}

The dual inhibition of protein kinases and HDACs has become the most popular choice for epigenetic multitarget drugs which is not surprising given the current importance placed on kinases in drug discovery. ${ }^{15}$ In the first publication to demonstrate this strategy, Mahboobi et al. designed a set of compounds that combine the features of HDAC inhibitors and the approved $A B L$ kinase inhibitor imatinib (23, Figure 6). ${ }^{16}$ Cell-based studies had already demonstrated additive effects when these agents were administered together, lending support to the multitarget strategy The hybrid compounds contained hydroxamic acids or benzamides as HDAC zinc-binding warheads attached through linkers to the imatinib scaffold. Examples 24 and 25 illustrate how variation of the zinc-binding warhead can affect HDAC isoform selectivity. Both compounds were micromolar inhibitors of the ABL, PDGFR- $\beta$ and VEGF-R2 kinases and antiproliferative at a micromolar level against HeLa and K562 cell lines. Interestingly, they were equipotent against both wildtype $A B L$ and the $T 315$ I mutant that is resistant to imatinib.

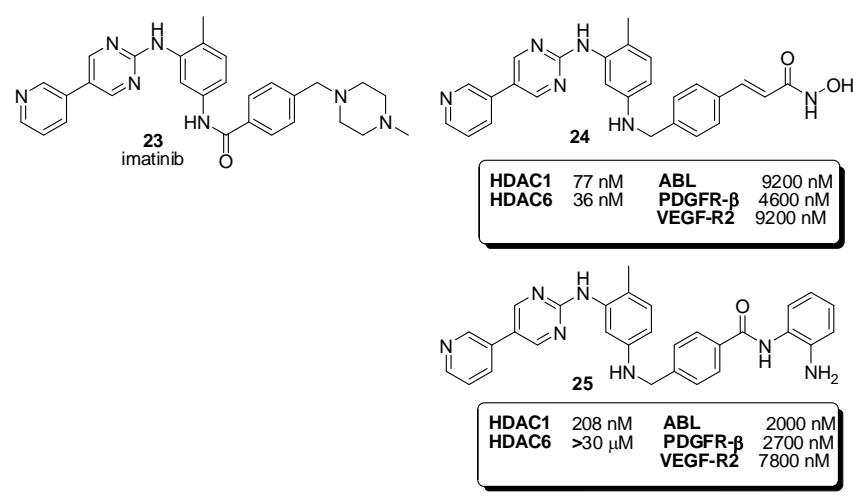

Figure 6. The structures of imatinib and analogues that are dual HDAC and kinase inhibitors. In this and subsequent figures, $\mathrm{IC}_{50}$ values where available in biochemical assays for the drug targets are shown.

The approved kinase inhibitor erlotinib (26, Figure 7) has served as the inspiration for dual HDAC inhibitors that target EGFR, HER2 and PDGFR. The X-ray cocrystal structure of erlotinib with EGFR indicates that the phenoxy substituents extend beyond the ATP binding pocket and should be amenable to homologation while retaining affinity. At Curis, erlotinib hybrids containing a zinc-binding hydroxamic acid and a spacer linked to the quinazoline scaffold were investigated. Variations in chain length and substitutions of the quinazoline and phenyl ring were examined and numerous analogues were found to be nanomolar inhibitors of HDACs, EGFR and HER2. ${ }^{17}$ From this series, CUDC-101 (27) emerged as the clinical candidate. A Phase I trial in twelve patients with intermediate or high risk head and neck squamous cell carcinoma was recently completed with promising results. ${ }^{18}$ Patients were treated with an intravenous dose of $275 \mathrm{mg} / \mathrm{m}^{2}$ of CUDC-101 three times weekly with concurrent cisplatin and radiotherapy over seven weeks. Pharmacodynamic analysis provided evidence of inhibition of both HDACs and EGFR in vivo. At 1.5 years of median follow-up, nine patients were free of disease progression, one had a recurrence and two had died (neither attributed to the drug). Five patients discontinued the drug due to an adverse event suggesting that the dosing schedule needs to be improved before a larger trial carried out.

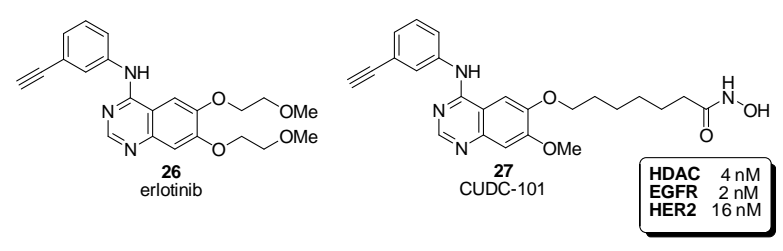

Figure 7. The approved EGFR inhibitor erlotinib and the dual inhibitor clinical candidate CUDC-101. Note: In this and subsequent figures, HDAC refers to an 
assay against a crude enzyme extract rather than a single recombinant isoform.

Independently, other groups have published dual inhibitors based on erlotinib. In a follow-up on their earlier work based on imatinib, Mahboobi et al. investigated both the hydroxamic acid and benzamide as zinc-binding motifs appended by rigid linkers to the quinazoline. ${ }^{19}$ The hydroxamic acid series exemplified by 28 (Figure 8) displayed higher inhibition of HDACs but was a modest kinase inhibitor compared to the benzamide 29. The differences in HDAC isoform selectivity between the two compounds are likely due to the different linkers rather than the change in zinc-binding warhead.

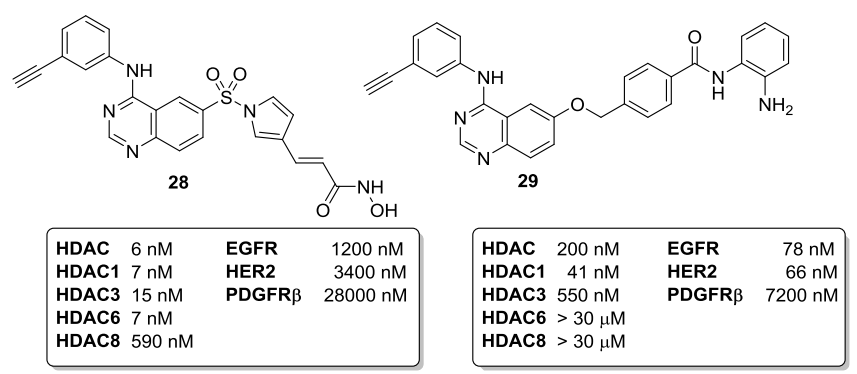

Figure 8. Structures of HDAC inhibiting erlotinib analogues.

In a less successful attempt, Zhang replaced the quinazoline scaffold with a substituted benzoic acid (30 and $\mathbf{3 1}$, Figure 9) but these hydroxamic acids were relatively poor in HDAC inhibition. ${ }^{20}$ Another group grafted the zinc-binding group onto the aryl ring of erlotinib rather than the quinazoline moiety (32 and 33). ${ }^{21}$ Not surprisingly, this resulted in weaker kinase inhibition compared to the above examples. The metasubstituted linker in $\mathbf{3 3}$ was significantly better in HDAC inhibition compared to the para-substituted $\mathbf{3 2}$ whereas the order of inhibition against kinases was reversed.

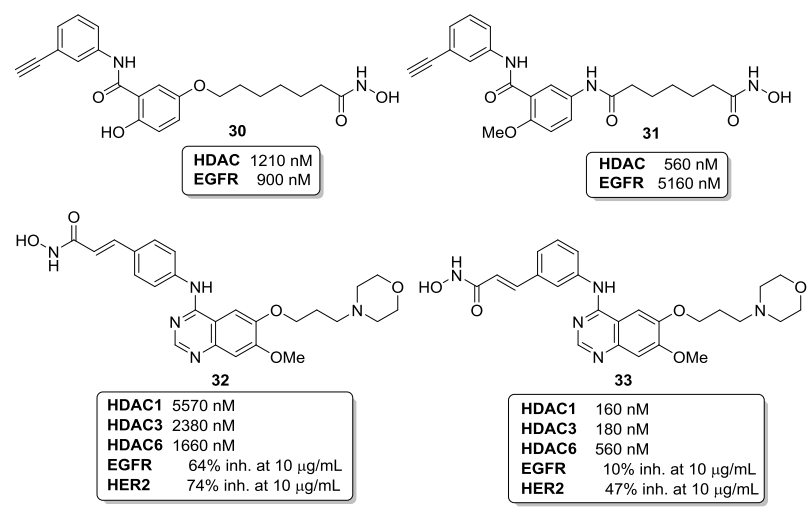

Figure 9. Dual EGFR and HDAC inhibitors.

Lapatinib (34, Figure 10), an EGFR/HER2 kinase inhibitor, was the starting point for a hybrid series reported by Mahboobi et al. ${ }^{22}$ The hydroxamic acid 35 is a nanomolar inhibitor of both HDACs and EGFR/HER2 kinases and a micromolar inhibitor of cancer cell lines. Meanwhile, $\mathbf{3 6}$ is a selective c-Src kinase inhibitor that has modest activity in cell-based assays. Synergistic effects were observed with panobinostat (12) and based on this finding a multitarget analogue was prepared by attaching a hydroxamic acid linker through alkene-azide 'click chemistry'. ${ }^{23}$ Unlike the majority of dual HDAC inhibitors in this review, $\mathbf{3 7}$ was profiled against the full set of isoforms and found to potently inhibit HDACs $1,3,6$ and 10 while retaining submicromolar activity against the kinase. Compound $\mathbf{3 7}$ was more active than vorinostat or dasatinib alone in a subset of the $\mathrm{NCl}$ panel of 60 cell lines and was antiproliferative at submicromolar levels.

Targeting kinases is not limited to inhibition, as for example the activation of protein kinase $\mathrm{C}(\mathrm{PKC})$ resulting in translocation to the cell membrane has therapeutic utility. A compound series inspired by the indolacatam natural product scaffold was investigated by Kozikowski as a dual PKC activator/HDAC inhibitor. ${ }^{24}$ The example $\mathbf{3 8}$ is a nanomolar PKC binder and activates the enzyme as evidenced by an enhancement of $\alpha$ secretase processing of amyloid precursor protein in cells at concentrations of 0.1-10 $\mu \mathrm{M}$. Metabolic cleavage of the thioester would release a free thiol predicted to be a HDAC inhibitor and an increase in histone $\mathrm{H} 4$ acetylation was observed at $10 \mu \mathrm{M}$ in cells.

Aside from protein kinases, the dual inhibition of HDACs and phosphatidylinositol 3-kinase (PI3K) was investigated at Curis by preparing hybrids of pictilisib (39), the first $\mathrm{P} 13 \mathrm{~K}$ inhibitor to enter clinical trials. This led to the candidate CUDC-907 (40), a potent nanomolar dual HDAC and pan-P13K inhibitor. ${ }^{25}$ The compound was effective in cell lines and a tumor xenograft model and is currently in Phase I clinical trials for lymphoma and solid tumors. ${ }^{26}$
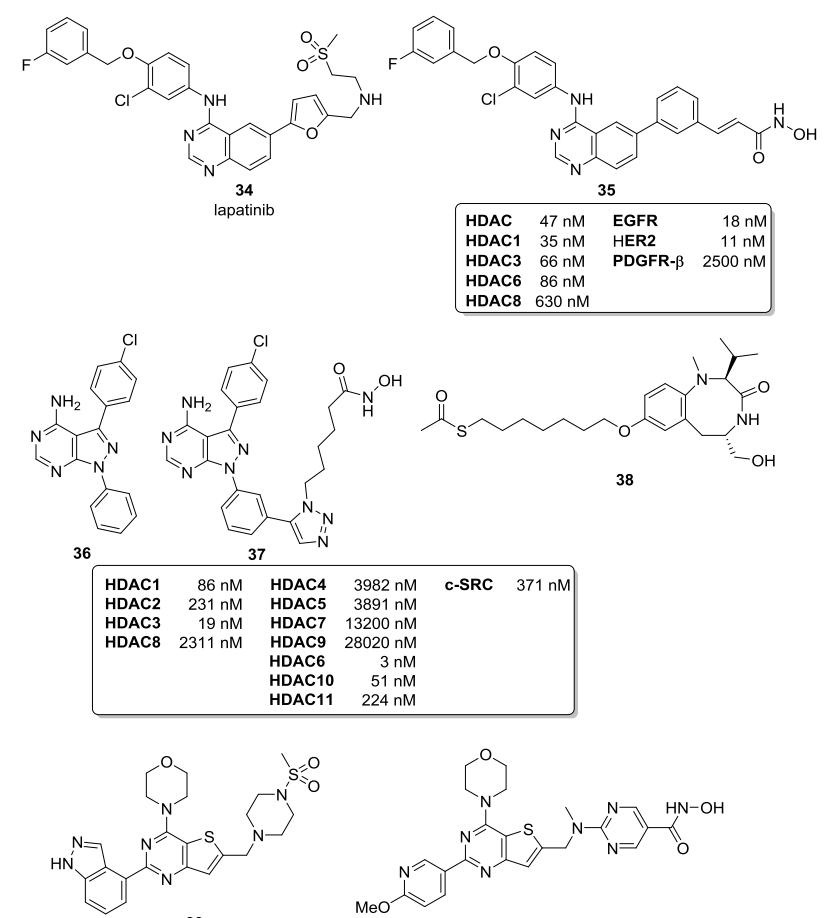

pictilisib 40
CUDC-907

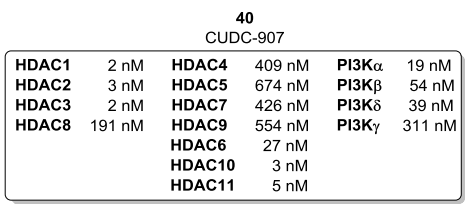


Figure 10. Dual HDAC inhibitors based on lapatinib, c-Src inhibitor 36, PKC activation and pictilisib.

\section{Dual inhibitors of HDACs and non-kinase enzymes}

There are a number of multitarget examples where a HDAC inhibitor acts upon a second non-kinase enzyme. In an early attempt, inhibition of inosine monophosphate dehydrogenase (IMPDH) for the treatment of chronic myelogenous leukemia was targeted. Mycophenolic acid (41, Figure 11) is a nanomolar IMPDH inhibitor used clinically as an immunosuppressant. ${ }^{27}$ The corresponding hydroxamic acid $\mathbf{4 2}$ retains activity against IMPDH and is additionally a micromolar HDAC inhibitor whereas mycophenolic acid itself is inactive against HDACs. ${ }^{28}$ Additional dual inhibitors were designed from synthetic IMPDH inhibitors such as Vertex's clinical candidate merimepodib (43), leading to 44 and $45 .{ }^{29}$ The compounds were antiproliferative at a micromolar level against the K562 cell line.

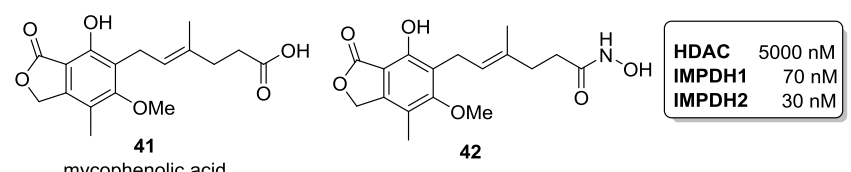<smiles>COc1cc(NC(=O)Nc2cccc(CNC(=O)OC3CCOC3)c2)ccc1-c1cnco1</smiles>

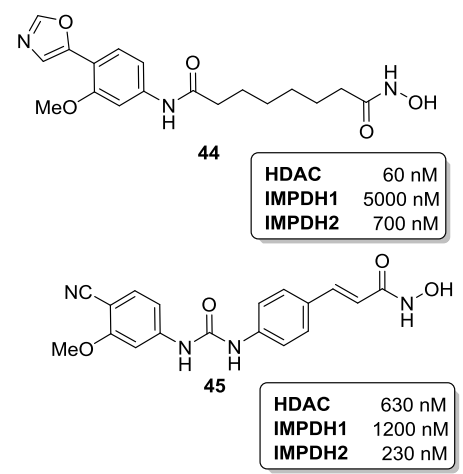

Figure 11. Dual HDAC and IMPDH inhibitors based on mycophenolic acid and merimepodib.

The statin inhibitors of 3-hydroxy-3-methylglutaryl coenzyme A reductase (HMGCR) have been used for decades to treat elevated cholesterol levels and are among the world's most prescribed drugs. ${ }^{30}$ Recent evidence suggests that HMGCR inhibitors have a beneficial effect in cancer. Fang et al. ring opened the lactone in the approved drug lovastatin (46, Figure 12) with hydroxylamine to obtain the hydroxamic acid 47 , a dual HMGCR and HDAC inhibitor. ${ }^{31}$ When administered orally, the compound was active in a colitis-associated colorectal cancer mouse model. Sildenafil (48) is another blockbuster drug that served as the seed for a dual inhibitor. ${ }^{32}$ As a phosphodiesterase 5 (PDE5) inhibitor, sildenafil is primarily used for the treatment of erectile dysfunction. It has been shown to restore cognitive defects in animal models, an outcome also observed with HDAC inhibitors. A Spanish patent describes dual inhibitors such as $\mathbf{4 9}$ that are brain-penetrant and show efficacy in mouse models for Alzheimer's disease. ${ }^{33}$

\section{Dual HDAC and DNA targeting agents}

There are a large number of anticancer drugs that act upon DNA either by direct binding or interference with enzymes involved in DNA biosynthesis or modification. ${ }^{34}$ Both these classes of compounds have been combined with HDAC inhibition to provide dual inhibitors. Cisplatin (50, Figure 13) is an approved drug that works by cross-linking of the DNA strands. The analogue $\mathbf{5 1}$ was shown to unwind DNA by an electrophoretic mobility shift assay in addition to being a micromolar HDAC1 inhibitor which however was approximately 8-fold less active in HDAC1 inhibition than the precursor malonic acid uncomplexed to $\mathrm{Pt} .{ }^{35}$ Bendamustine (52) is another DNA crosslinking nitrogen mustard used in the treatment of leukemia and lymphomas and is in the WHO's List of Essential Medicines. The hydroxamic acid analogue $\mathbf{5 3}$ is a nanomolar HDAC inhibitor and was superior to bendamustine in a BCR-ABL-driven acute lymphoblastic leukemia mouse model. ${ }^{36}$

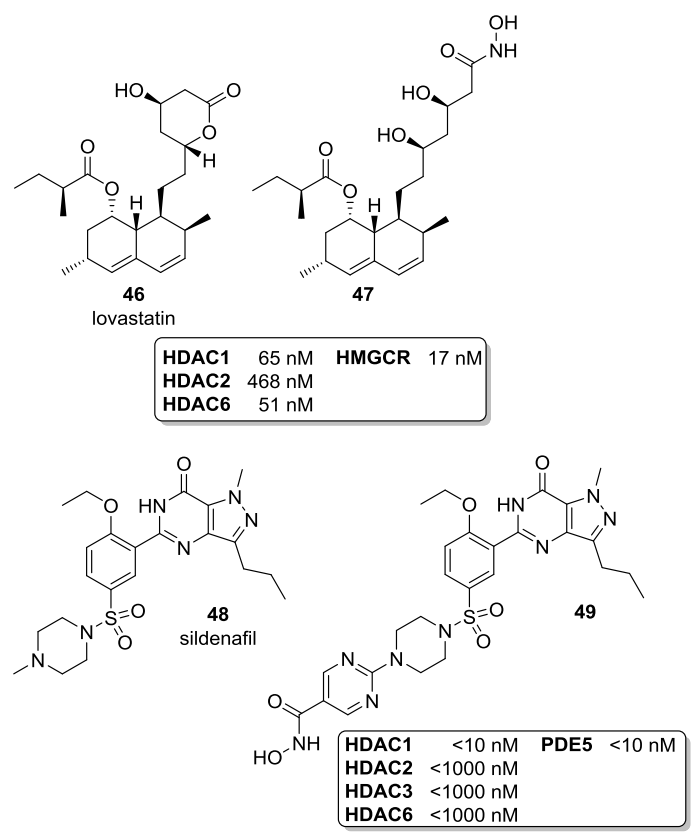

Figure 12. HMGCR and PDE5 dual HDAC inhibitors

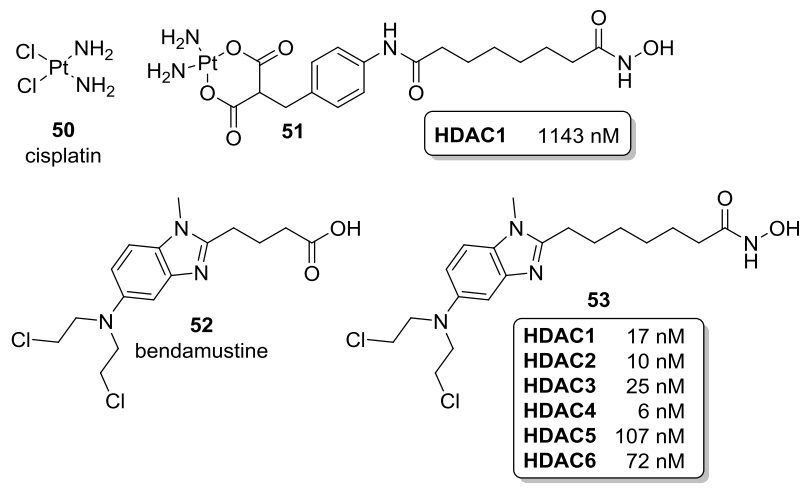

Figure 13. Combining DNA covalent modification and HDAC inhibitors. 
The DNA topoisomerases (Topo I and Topo II) are an important anticancer target. Several topoisomerase inhibitors are in use clinically and exert their action by formation of a ternary complex with the enzyme and DNA substrate. Oyelere was the first to report a dual HDAC/topoismerase inhibitor. ${ }^{37,38}$ The potent natural product daunorubicin (54, Figure 14, an approved Topo II inhibitor) and camptothecin (55, a Topo I inhibitor with approved semisynthetic derivatives) were the starting materials. Daunorubicin was linked with a hydroxamic acid bearing aldehyde by reductive alkylation to provide 56 while camptothecin was connected to a hydroxamic acid by a triazole spacer to give 57. Besides being nanomolar HDAC inhibitors and antiproliferative in cancer cell lines, these compounds inhibited topoisomerase as assessed by DNA decatenation and plasmid relaxation assays respectively for $\mathbf{5 6}$ and $\mathbf{5 7}$.
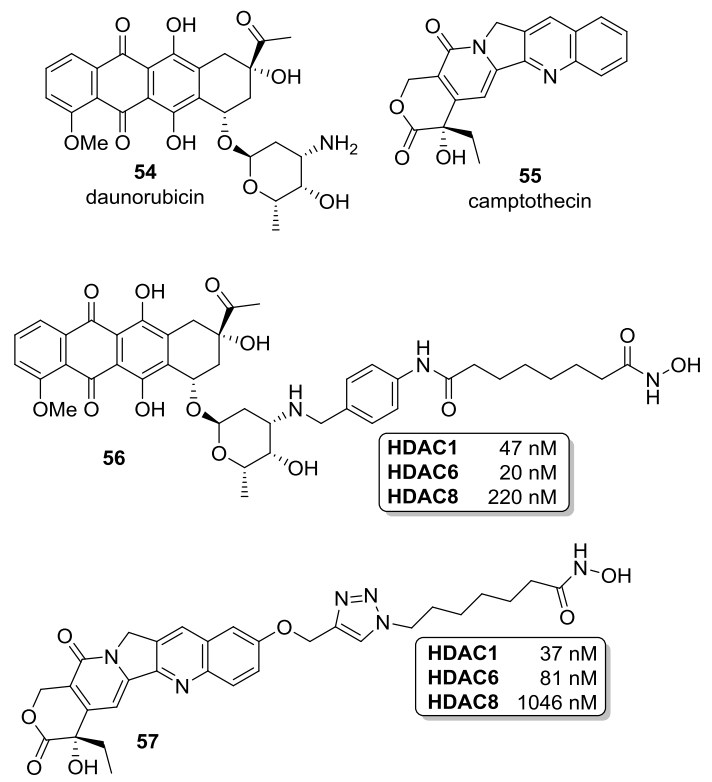

Figure 14. Dual HDAC and topoismerase inhibitors.

Other groups have prepared dual topoisomerase/HDAC inhibitors based on the natural products podophyllotoxin (58, Figure 15), evodiamine (59) and the synthetic compound $\mathbf{6 0}$. In addition to HDAC inhibition, the podophyllotoxin derivative 61 inhibited Topo II in a DNA relaxation assay. ${ }^{39}$ While acridine 60 is a dual Topo I and II inhibitor, the related hydroxamic acid $\mathbf{6 2}$ only inhibited Topo I in DNA relaxation and cleavable-complex formation assays. ${ }^{40}$ The compound showed efficacy in a prostate cancer xenograft model. The idea of combining HDAC inhibition with Topo I/II inhibition to give a triple inhibitor was realized with the evodiamine analogue $63 .{ }^{41}$ In addition to HDAC inhibition, the compound inhibited both Topo I and II in DNA relaxation assays and was antiproliferative at micromolar levels.
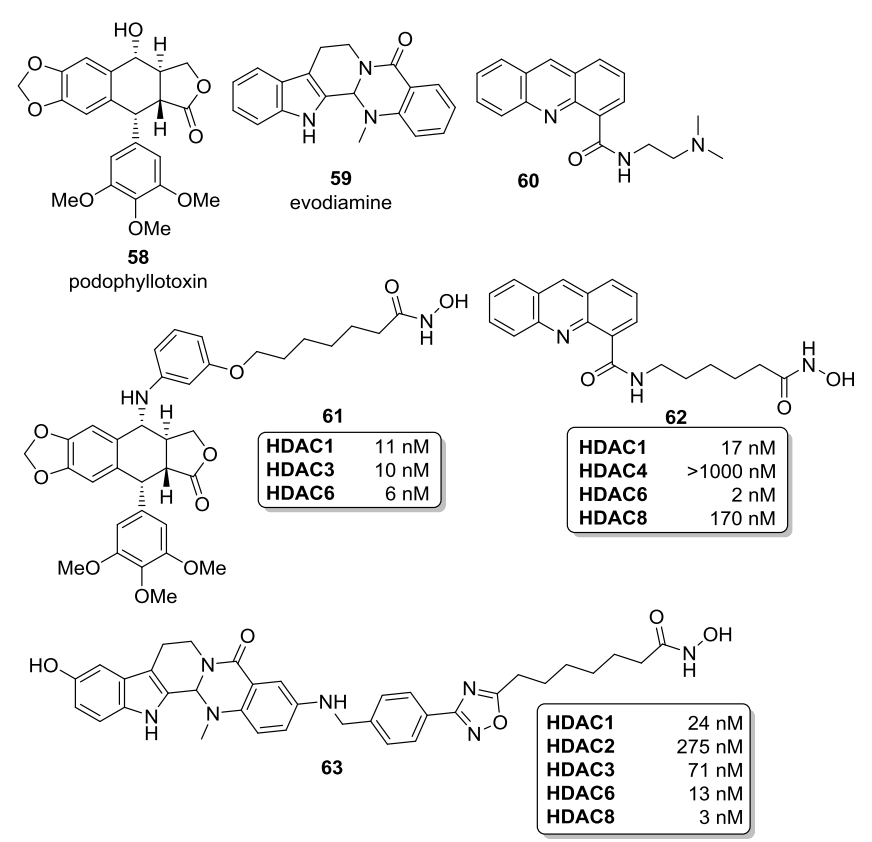

Figure 16. Dual HDAC and topoismerase inhibitors.

\section{Dual epigenetic and receptor ligands}

Upon ligand activation, members of the nuclear receptor superfamily translocate to the nucleus and bind to their corresponding DNA response elements. ${ }^{42}$ Combination studies have demonstrated synergistic effects between ligands for these receptors and HDAC inhibitors, suggesting the feasibility of dual targeting. The natural hormone 1,25-dihydroxyvitamin D3 (64, Figure 17, 1,25D) and the synthetic ligand LG190178 (65) bind to the nuclear vitamin $D$ receptor (VDR) and were the template for hydroxamic acids 66 and 67 respectively. ${ }^{43,44,45}$ In cell-based assays, the hydroxamic acids exhibited effects due to combined VDR binding and HDAC inhibition.

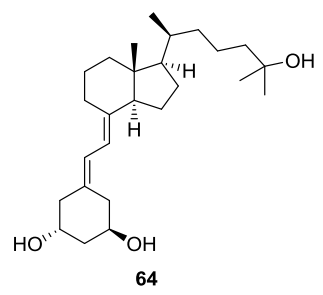<smiles>CCC(C)(c1ccc(OCC(O)CO)c(C)c1)c1ccc(OCC(O)C(C)(C)C)c(C)c1</smiles>

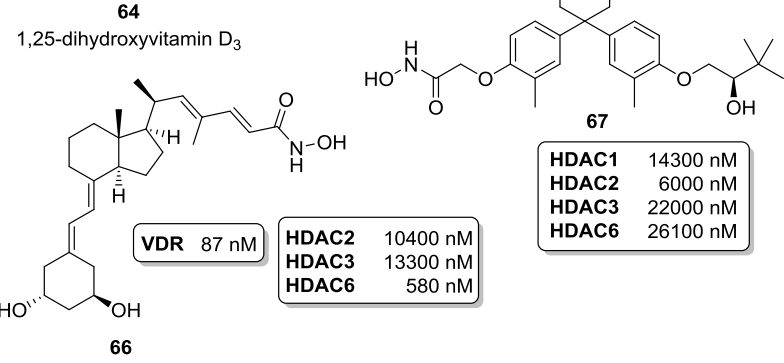

Figure 17. HDAC inhibitors with dual VDR agonist activity. 
anticancer drugs that bind to the retinoid $X(R X R)$ and estrogen receptors (ER) respectively. Bexarotene is an interesting choice for combination with a HDAC inhibitor since both drugs are clinically used for the treatment of cutaneous T-cell lymphoma. The hydroxamic acid derivative $\mathbf{7 0}$ displayed dual targeting effects in cell-based assays. ${ }^{46}$ In the case of raloxifene and other ER ligands, their value lies in the treatment of $\mathrm{ER}(+)$ breast cancers that are hormone-dependent. Reactivation of genes by HDAC inhibitors has been proposed to resensitize $\operatorname{ER}(-)$ hormoneindependent cancers to ER ligands. Among a library of raloxifene hydroxamic acid analogues, one compound $\mathbf{7 1}$ was active against $\mathrm{ER}(-)$ cell lines confirming a dual mechanism of action. ${ }^{47}$<smiles>C=C(c1ccc(C(=O)O)cc1)c1cc2c(cc1C)C(C)(C)CCC2(C)C</smiles><smiles>O=C(c1ccc(OCCN2CCCCC2)cc1)c1c(-c2ccc(O)cc2)sc2cc(O)ccc12</smiles><smiles>C=C(c1ccc(C(=O)NO)cc1)c1cc2c3c(c1)CCC(C)(C)CC3CCCC2</smiles><smiles>O=C(CCCCc1cn(-c2ccc(C(=O)c3c(-c4ccc(O)cc4)sc4cc(O)ccc34)cc2)nn1)NO</smiles>

Figure 18. Dual HDAC inhibitors based on RXR and ER ligands.

Many natural products comprising diverse chemical structures disrupt the microutubule network by either promoting or inhibiting the polymerization of tubulin. Some of these have led to important anticancer drugs including paclitaxel and vinblastine. ${ }^{48}$ Colchicine (72, Figure 19) contains an amide that can be varied without loss of its polymerization inhibiting activity. Taking advantage of this SAR, dual inhibitors $\mathbf{7 3}$ and $\mathbf{7 4}$ were prepared that contain a hydroxamic acid and benzamide sidechain respectively. ${ }^{49,50}$ The analogues enforced $G_{2} / M$ cell cycle consistent with microtubule disruption in addition to being micromolar HDAC inhibitors. In 74, addition of the thiophene moiety to the benzamide conferred selectivity towards HDAC2. The same group also reported a series derived from the 4-deoxy analogue of podophyllotoxin (58), an inhibitor of tubulin polymerization. The HDAC inhibitory activity of benzamide $\mathbf{7 5}$ was modest against the three isoforms tested. ${ }^{51}$
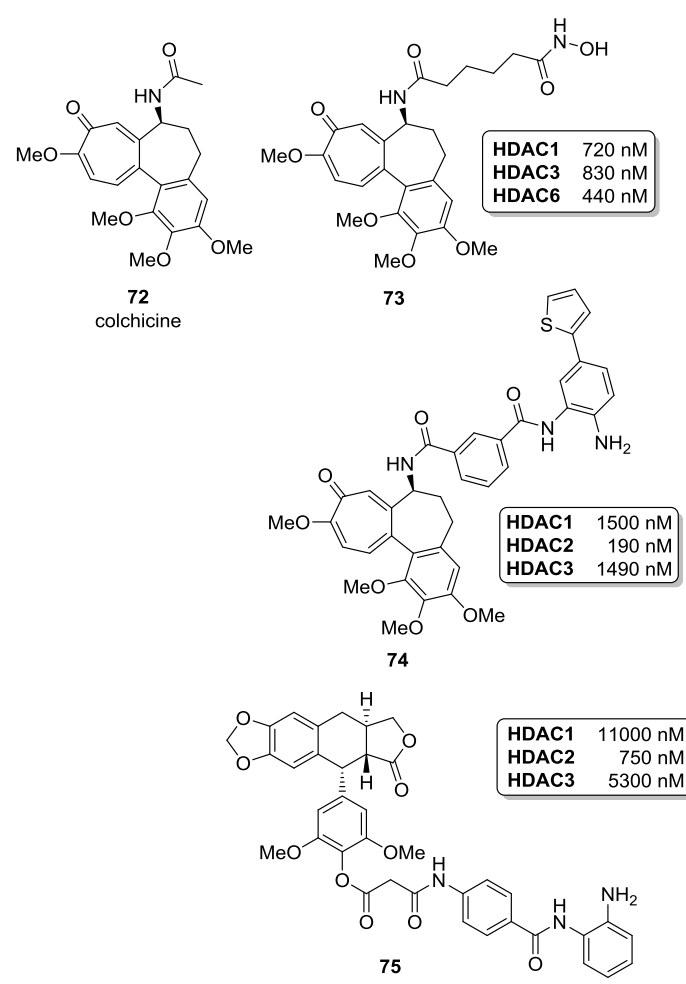

Figure 19. Dual HDAC and tubulin polymerization inhibitors.

The RAS small GTPase is part of the ERK signaling cascade and approximately a third of human tumors contain mutant forms of RAS that are constitutively active. ${ }^{52}$ RAS is localized at the membrane by prenylation at the C-terminus. The farnesylated thiosalicylic acid salirasib (76, Figure 20) competes with both farnesyl and geranylgeranyl RAS isoforms to inhibit their membrane localization as well as formation of the mTOR-raptor complex. As the drug acts in synergy with HDAC inhibitors, it is a candidate for multitargeting. The hydroxamic acid 77 is a submicromolar HDAC inhibitor and interferes with RAS signaling as demonstrated by decreased cellular levels of phospho-Akt and phospho-ERK1/2, and was more potent than salirasib in growth inhibition of cancer cell lines. ${ }^{53}$ Like ERK, Wnt/ $\beta$-catenin signaling is another pathway that is often aberrantly activated in human cancers. $^{54}$ The seven-transmembrane protein smoothened (SMO) is one of the components in this pathway and the SMO antagonist vismodegib (78) has recently received approval for the treatment of basal cell carcinoma and is synergistic with HDAC inhibitors. The hydroxamic acid analogue 79 inhibited both HDAC isoforms and SMO-mediated signaling at a nanomolar level. ${ }^{55}$ In support of a dual mechanism of action, 79 retained activity against cells with a mutant form of SMO and downregulated the expression of Gli-2, effects which are not observed with vismodegib on its own.

In a different approach, rather than modifying a receptor ligand, the benzamide clinical candidate HDAC inhibitor entinostat was conjugated with a nitric oxide (NO) donor to give $\mathbf{8 0 . 5 6}$ The hybrid compound inhibits HDACs at a micromolar level as well as releasing NO leading to the activation of soluble guanylyl cyclase. 


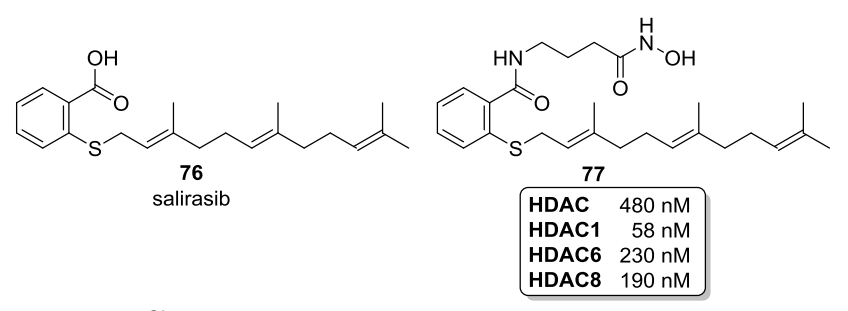<smiles>CS(=O)(=O)c1ccc(C(=O)Nc2ccc(Cl)c(-c3ccccn3)c2)c(Cl)c1</smiles>

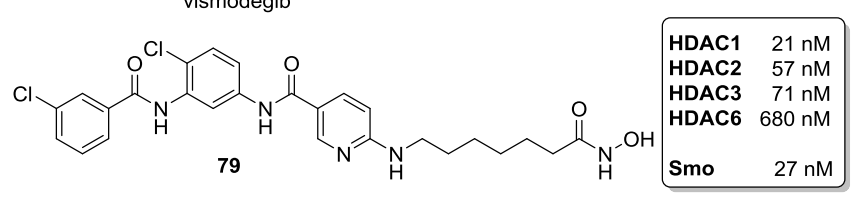<smiles>CN(Cc1ccc(COC(=O)NCc2ccc(C(=O)Nc3ccccc3N)cc2)cn1)Cc1no[n+]([O-])c1[O-]</smiles>

Figure 20. HDAC inhibitors that disrupt ERK, Wnt/ß-catenin and NO signaling.

The drug thalidomide (81, Figure 21) was originally used as a sedative before being banned due to the teratogenic side effects of one enantiomer. Subsequently, there has been renewed interest in the drug's immunomodulatory properties and the analogues lenalidomide and pomalidomide are approved for the treatment of multiple myeloma. Recently, the molecular target of thalidomide was identified as cereblon, a component of the cullindependent ubiquitin ligase that targets bound protein partners for degradation by the proteasome. ${ }^{57}$ Both Bradner and Crews have designed multitarget drugs that link the bromodomain ligand JQ1 to the thalidomide scaffold. Bradner's compound $\mathbf{8 2}$ resulted in a selective and increased degradation of BRD2, BRD3 and BRD4 and induced apoptosis more rapidly and potently than JQ1 in leukemia cell lines. ${ }^{58}$ At $50 \mathrm{mg} / \mathrm{kg}$, the compound showed significant activity in reducing tumor progression in a murine leukemia xenograft model. Crews's ligand $\mathbf{8 3}$ featured a longer connector between JQ1 and the thalidomide and was a nanomolar ligand for BD1 and BD2, the two bromodomains in BRD4. ${ }^{59}$ Compound $\mathbf{8 3}$ inhibited $\mathrm{B}$ cell proliferation at a higher level than JQ1 or pomalidomide alone.

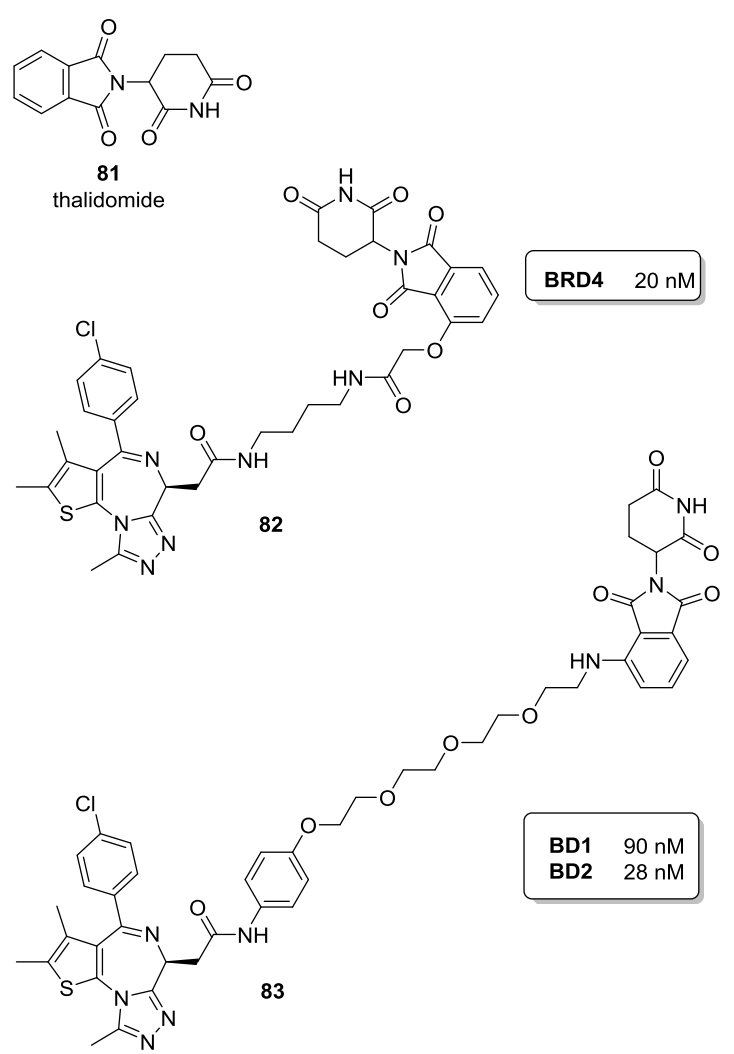

Figure 21. Bromodomain ligand-thalidomide hybrids that target the bromodomain for cereblon-mediated degradation.

\section{Dual epigenetic targeting}

There are several examples where two epigenetic targets have been addressed by a single molecule. Investigation of a set of dienones with similarities to the natural product curcumin (84, Figure 22), a promiscuous hit in various biological assays, ${ }^{60}$ led to compounds such as 85. Although $\mathrm{IC}_{50}$ values were not determined, micromolar activity was observed against p300/CBP (a histone acetyltransferase), SET7 (a lysine methyltransferase) and the SIRT1 and SIRT2 lysine deacetylases. ${ }^{61}$ The dimeric marine natural product psammaplin A (86) is reported to inhibit both DNMTs and HDACs. ${ }^{62}$ An SAR study identified the indole analogue 87 as a dual inhibitor of both targets as well as sirtuins. ${ }^{63}$ Meanwhile, the DNMT inhibitory activity of the natural product has been called into question by another group. ${ }^{64}$ 
<smiles>COc1cc(/C=C/C(=O)/C=C(O)/C=C/c2ccc(O)c(OC)c2)ccc1O</smiles><smiles>O=C(NCCSSCCNC(=O)C(Cc1ccc(O)c(Br)c1)=NO)C(Cc1ccc(O)c(Br)c1)=NO</smiles><smiles></smiles>

Figure 22. Natural product inspired dual epigenetic inhibitors.

By appending a metal-binding moiety to the KDM1 inhibitor tranylcypromine (17), a pan-histone demethylase inhibitor 88 (Figure 23) that acts upon lysine-specific demethylase as well as a set of Jumonji $\mathrm{C}$ demethylases at a micromolar level was realized. ${ }^{65}$ The compound induced apoptosis in LNCaP prostate cancer and HCT116 colon cancer cell lines and increased methylation at histone residues $\mathrm{H} 3 \mathrm{~K} 4$ and $\mathrm{H} 3 \mathrm{~K} 9$ was observed. GlaxoSmithKline have reported the modification of tetrahydroquinoline bromodomain ligands to give rise to the hydroxamic acid 89. Although the compound displayed antiproliferative effects, no synergy was observed over cellular treatment with the combination of a bromodomain ligand and a HDAC inhibitor. ${ }^{66}$

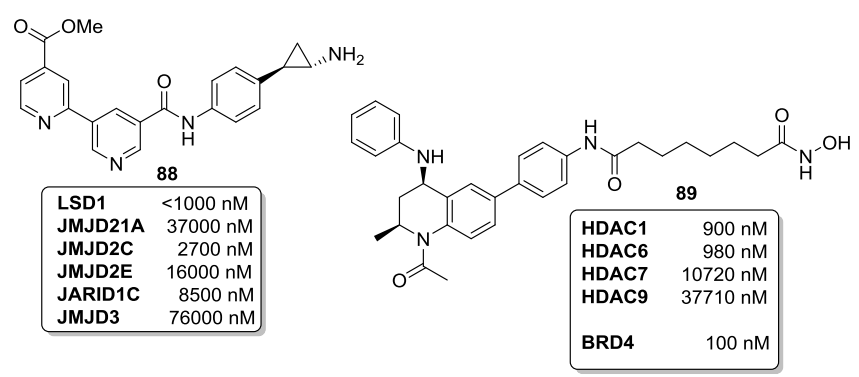

Figure 23. Dual demethylase and bromodomain targeting compounds

\section{Off-target or dual target}

In the previous sections, we have examined examples whereby a multitarget drug has deliberately been engineered. In addition, there are instances where an off-target effect has been discovered for a drug with an established mechanism of action. The first approved HDAC inhibitor vorinostat (9, Figure 24) contains a hydroxamic acid warhead which is responsible for its activity. It might be expected that the hydroxamic acid would have additional activity against other targets through metal binding. The JmjC family of lysine demethylases contain an active site iron cation and vorinostat was found to inhibit the demethylase JMJD2E at a micromolar level. ${ }^{67}$ Although this is unlikely to be physiologically relevant, vorinostat was more active than $\mathrm{N}$-oxalyl glycine (90), a standard inhibitor of 2-oxoglutarate and iron(II)dependent dioxygenases. The second approved HDAC inhibitor romidepsin (10) was also recently identified to have an unexpected off-target effect, inhibiting $\mathrm{PI} I \mathrm{~K}$ with an $\mathrm{IC}_{50}$ of approximately $50 \mu \mathrm{M} .{ }^{68}$ By screening a set of synthetic analogues of the natural product, the lead $\mathbf{9 1}$ was discovered with an improved $\mathrm{IC}_{50}$ of $6.7 \mu \mathrm{M}$. $^{69}$

A set of 628 kinase inhibitors was screened for competition against an acetylated histone $\mathrm{H} 4$ peptide in binding to the BRD4 bromodomain. ${ }^{70}$ Interestingly, nine of the compounds displayed $>90 \%$ inhibition at a concentration of $50 \mu \mathrm{M}$. Volasertib (92), an inhibitor of the Polo-like kinase in Phase III clinical trials, ${ }^{71}$ bound to the BRD4 bromodomain in an isothermal titration calorimetry assay. In cells, the drug affected biomarkers associated with BRD4 at a concentration of $300 \mathrm{nM}$. As BRD4 has been implicated as contributing towards acute myeloid leukemia (AML), its antagonism by volasertib may contribute to therapeutic benefit in addition to the drug's primary function of kinase inhibition. The study also identified fedratinib (93), a JAK2 inhibitor that reached Phase III trials before being discontinued, as a dual BRD4 ligand.
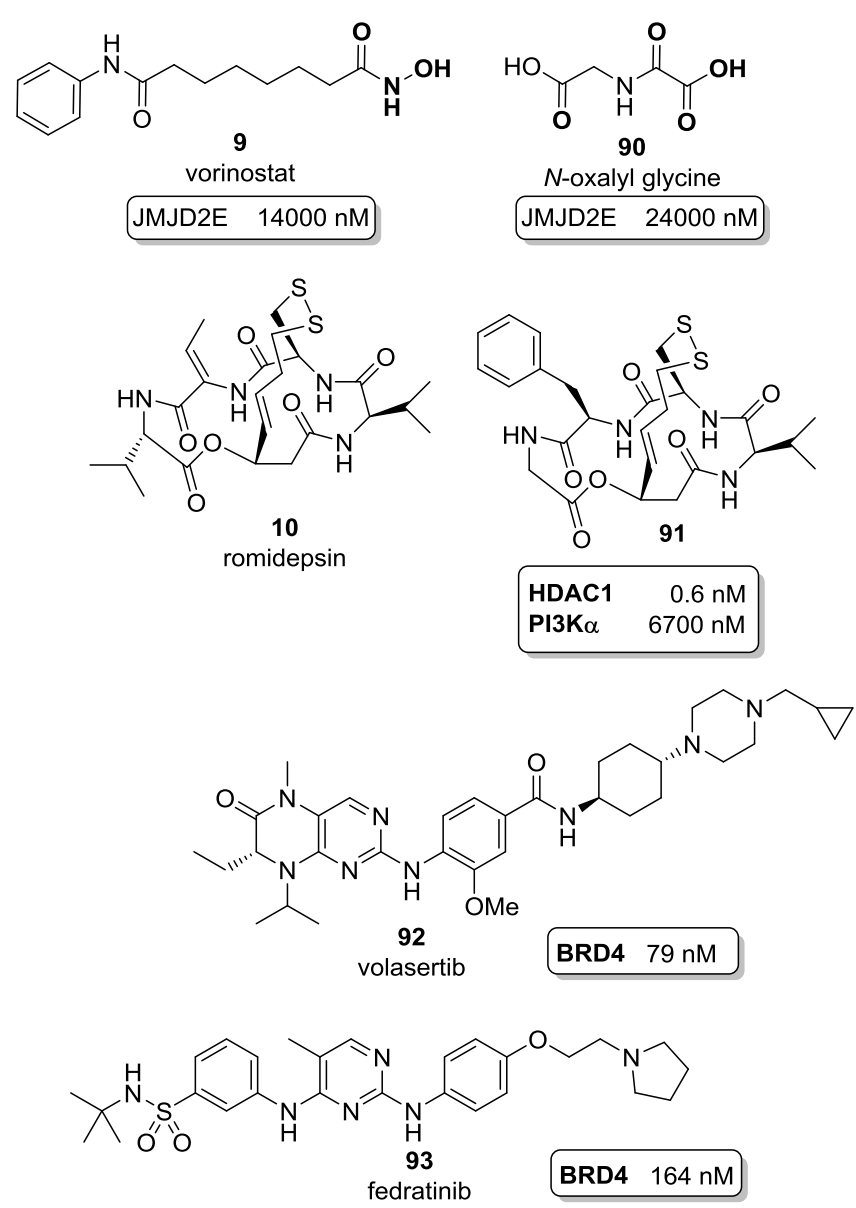

Figure 24. Examples of dual targets discovered with clinical candidates and approved drugs.

\section{Epigenetic multitarget drugs: progress and prospects}

In 2007, Pankiewic reported mycophenolic acid derivative 42, the 
first dual inhibitor aimed at an epigenetic target. Since then, there has been a steady stream of over five examples annually in recent years (Figure 25). With two exceptions, 81-82 that target the bromodomain and cereblon and $\mathbf{8 7}$ which is a dual LSD1 and JmjC demethylase inhibitor, all the others include HDAC inhibition as one of their mechanisms of action. This is a testament to the high flexibility offered by the HDAC pharmacophore as long as the zinc-binding warhead and the spacer are retained. Furthermore, the biology of HDACs and strategies for their inhibition are better understood than that of newer epigenetic targets. To date, HDAC inhibition has been combined with the following targets: $A B L$, EGFR, HER2, JAK, PDGFR, P13K, PLK, SrC and VEGFR kinases; inosine monophosphate dehydrogenase; HMG-CoA reductase; phosphodiesterase type 5; DNA crosslinking; DNA alkylation; topoisomerase; vitamin $\mathrm{D}$ receptor; retinoid $\mathrm{X}$ receptor; estrogen receptor; tubulin; RAS localization; smoothened and guanylyl cyclase. It has also been possible to address two epigenetic targets simultaneously by dual inhibition of HDACs and DNA methyltransferases, sirtuins, Jumonji $C$ demethylases and bromodomains. While this is an impressive list, it is undoubtedly growing and future publications will provide further examples.

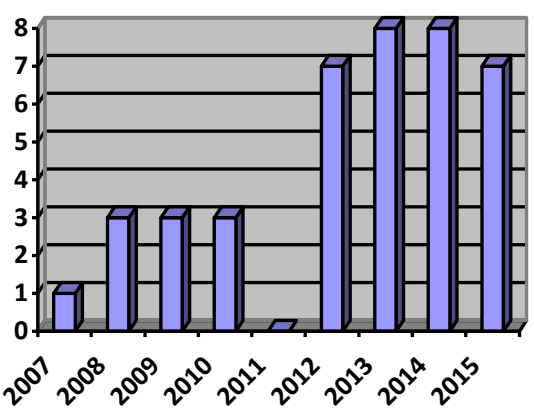

Figure 25. Publication year of multitarget epigenetic drugs cited.

The challenges for the future in this area remain the same as for all multitarget drugs. Firstly, the compounds need to be synthetically tractable. In some examples, this was accomplished in a concise manner by taking an existing molecule containing a carboxylic acid and converting it into a zinc-binding hydroxamic acid. However, in the majority of cases, more complex multistep routes were needed. Secondly, the resulting compound must possess high affinity for both of the intended targets. This is a major hurdle that is not easy to meet even with the seemingly permissive pharmacophore of the HDAC inhibitors. In this review, only a select handful of the compounds inhibit both their intended targets with $\mathrm{IC}_{50}$ values $\leq 100 \mathrm{nM}$ : 27, 29, 35, 40, 47, 49, 79 and 92. Furthermore, this level of activity needs to be achieved without sacrificing physicochemical guidelines for drug-like matter that compromise cellular or in vivo applications. Then there is the question of which targets will have the biggest impact when combined with an epigenetic mechanism of action in a dual inhibitor. Thus far, this has been guided by observed synergy using drug combinations. Nevertheless, once the desired compound has been synthesized, there must be robust evidence from biochemical assays as well as cell-based biomarkers that both targets are engaged at a meaningful concentration. This comes back to the need for high potency, as otherwise the compound may predominantly act against one target with a modest effect against the other that may be insignificant compared to serendipitious improvements in pharmacokinetics. Despite these fundamental issues, a tremendous amount of progress has been made by academia as well as industry in the last decade. A number of epigenetic multitarget drugs are active in animal models and two dual HDAC/kinase inhibitors $\mathbf{2 7}$ and $\mathbf{4 0}$ from Curis have already advanced to clinical trials. The future looks bright for dual inhibitors with an epigenetic flavor and more success stories can be anticipated with confidence.

\section{Acknowledgements}

The cosT Action CM1406 'Epigenetic Chemical Biology' is acknowledged for financial support.

Keywords: multitarget drugs• dual inhibitors• epigenetics• cancer $\bullet$ histone deacetylases (HDACs) 
A. Ganesan is Professor of Chemical Biology and Head of Medicinal Chemistry at the School of Pharmacy, University of East Anglia, Norwich, United Kingdom. He has held previous appointments at the National University of Singapore and the University of Southampton. His research interests include chemical biology, medicinal chemistry and biologically active natural products. $\mathrm{He}$ is Chair of the COST Action CM1406 Epigenetic Chemical Biology, a member of the IUPAC Subcommittee for Medicinal Chemistry and Drug Development and cofounder of Karus Therapeutics.

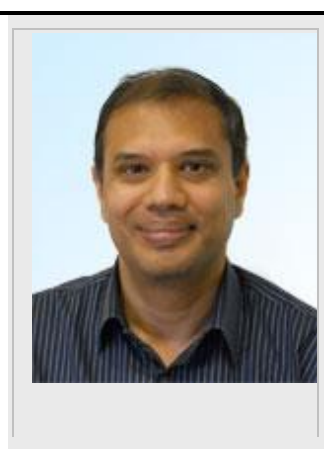

[15] Reviews on kinases: a) M. Rask-Andersen, J. Zhang, D. Fabbro, H. B. Schiöth, Trends Pharmacol. Sci. 2014, 35, 604-620; b) O. Hantschel, ACS Chem. Biol. 2015, 10, 234-245.

[16] S. Mahboobi, S. Dove, A. Sellmer, M. Winkler, E. Eichhorn, H. Pongratz, T.Ciossek, T. Baer, T. Maier, T. Beckers, J. Med. Chem. 2009, 52, 2265-2279.

[17] X. Cai, H. X. Zhai, J. Wang, J. Forrester, H. Qu, L. Yin, C. J. Lai, R. Bao, C. Qian, J. Med. Chem. 2010, 53, 2000-2009.

[18] T. J. Galloway, L. J. Wirth, A. D. Colevas, J. Gilbert, J. E. Bauman, N. F. Saba, D. Raben, R. Mehra, A. W. Ma, R. Atoyan, J. Wang, B. Burtness A. Jimeno, Clin. Cancer Res. 2015, 21, 1566-1573.

[19] T. Beckers, S. Mahboobi, A. Sellmer, M. Winkler, E. Eichhorn, H. Pongratz, T. Maier, T. Ciossek, T. Baer, G. Kelter, H.-H. Fiebig, M Schmidt, Med. Chem. Commun. 2012, 3, 829-835.

[20] M. Zuo, Y.-W. Zheng, S.-M. Lu, Y. Li, S.-Q. Zhang, Bioorg. Med. Chem 2012, 20, 4405-4412.

[21] X. Zhang, M. Su, Y. Chen, J. Li, W. Lu, Molecules 2013, 18, 6491-6503.

[22] S. Mahboobi, A. Sellmer, M. Winkler, E. Eichhorn, H. Pongratz, T. Ciossek, T. Baer, T. Maier, T. Beckers, J. Med. Chem. 2010, 53, 85468555

[23] K. S. Ko, M. E. Steffey, K. R. Brandvold, M. B. Soellner, ACS Med Chem. Lett. 2013, 4, 779-783.

[24] A. P. Kozikowski, Y. Chen, T. Subhasish, N. E. Lewin, P. M. Blumberg, Z. Zhong, M. A. D'Annibale, W.-L. Wang, Y. Shen, B. Langley, ChemMedChem 2009, 4, 1095-1105.

[1] Reviews on epigenetics: a) T. Suganuma, J. L. Workman, Annu. Rev. Biochem. 2011, 80, 473-499; b) S. B. Rothbart, B. D. Strahl, Biochim. Biophys. Acta 2014, 1839, 627-643; c) C. Deans, K. A. Maggert Genetics 2015, 199, 887-896; d) R. K. McGinty, S. Tan, Chem. Rev. 2015, 115, 225-2273; e) G. D. Bowman, M. G. Poirier, Chem. Rev. 2015, 115, 2274-2295

[2] Reviews on epigenetic drug discovery: a) B. Pachiayappan, P. M. Woster, Bioorg. Med. Chem. Lett. 2014, 24, 21-32. b) A. Finley, R. A Copeland, Chem. Biol. 2014, 21, 1196-1210.

[3] Reviews on DNMTs: a) J. Lan, S. Hua, X. He, Y. Zhang, Acta Biochim. Biophys. Sin. 2010, 42, 243-252; b) J. Fahy, A. Jeltsch, P. B. Arimondo, Expert Opin. Ther. Patents 2012, 22, 1427-1442.

[4] Reviews on TETs: a) W. A. Pastor, L. Aravina, A. Rao, Nat. Rev. Mol. Cell Biol. 2013, 14, 341-356; b) X. Lu, B. S. Zhao, C. He, Chem. Rev. 2015, 115, 2225-2239.

[5] Reviews on HATs: a) H. Yuan, R. Marmorstein, Biopolym. 2013, 99 98-111; b) B. M. Dancy, P. A. Cole, Chem. Rev. 2015, 115, 2225-2239.

[6] Reviews on HDACs: a) F. F. Wagner, M. Weïwer, M. C. Lewis, E. B. Holson. Neurotherapeutics 2013, 10, 589-604; b) M. Mottamal, S. Zheng, T. L. Huang, G. Wang, Molecules 2015, 20, 3898-3941.

[7] Reviews on sirtuins: a) J. M. Villalba, F. J. Alcaín, BioFactors 2012, 38, 349-359; b) H. Jing, H. Lin, Chem. Rev. 2015, 115, 2350-2375.

[8] Review on histone acylation: H. Huang, S. Lin, B. A. Garcia, Y. Zhao, Chem. Rev. 2015, 115, 2376-2418.

[9] Review on HDAC X-ray structures: C. Micelli, G. Rastelli, Drug Discovery Today 2015, 20, 718-735.

[10] Reviews on KMTs: a) C. Hui, T. Ye, Front. Chem. 2015, 3, 44; b) H. Ü. Kaniskan, K. D. Konze, J. Jin, J. Med. Chem. 2015, 58, 1596-1629.

[11] Reviews on PRMTs: a) M. Schapira, R. F. de Freitas, Med. Chem. Commun. 2014, 5, 1779-1788; b) J. Fuhrmann, K. W. Clancy, P. R. Thompson, Chem. Rev. 2015, 115, 5413-5461.

[12] Reviews on KDMs: a) T. Maes, E. Carceller, J. Salas, A. Ortega, C. Buesa, Curr. Opin. Pharmacol. 2015, 23, 52-60; b) J. M. Burg, J. E. Link, B. S. Morgan, F. J. Heller, A. E. Hargrove, D. G. McCafferty, Biopolym. 2015, 104, 213-246; c) Y. Zheng, J. Ma, Z. Wang, J. Li, B. Jiang, W. Zhou, X. Shi, X. Wang, W. Zhao, H. Liu, Med. Res. Rev. 2015, 35, 1032-1071.

[13] Reviews on BRDs: a) P. Filippakopoulos, S. Knapp, Nat. Rev. Drug Discovery 2014, 13, 337-356; b) M. Brand, A. M. Measures, B. G. Wilson, W. A. Cortopassi, R. Alexander, M. Höss, D. S. Hewings, T. P. C. Rooney, R. S. Paton, S. J. Conway, ACS Chem. Biol. 2015, 10, $22-$ 39.

[14] R. Álvarez, L. Altucci, H. Gronemeyer, A. de Lera, Curr. Top. Med. Chem. 2011, 11, 2749-2787.
[25] X. Cai, H. Zhai, C. Lai, C. Qian, R. Bao, world patent 135571, 2012

[26] C. Qian, C.-J. Lai, R. Bao, D.-G. Wang, J. Wang, G.-X. Xu, R. Atoyan H. Qu, L. Yin, M. Samson, B. Zifcak, A. W. S. Ma, S. DellaRocca, M. Borek, H.-X. Zhai, X. Cai, M. Voi, Clin. Cancer Res. 2012, 18, 4104 4113 3801-3826.

[28] L. Chen, D. Wilson, H. N. Jayaram, K. W. Pankiewic, J. Med. Chem 2007, 50, 6685-6691.

[29] L. Chen, R. Petrelli, G. Gao, D. J. Wilson, G. T. McLean, H. N. Jayaram Y. Y. Sham, K. W. Pankiewic, Bioorg. Med. Chem. 2010, 18, 59505964.

[30] Review on HMG-CoA reductase inhibitors: P. A. C. McPherson, MiniRev. Med. Chem. 2012, 12, 1250-1260.

[31] J.-B. Chen, T.-R. Chern, T.-T. Wei, C.-C. Chen, J.-H. Lin, J.-M. Fang, J. Med. Chem. 2013, 56, 3645-3655.

[32] Review on PDE5 inhibitors: P. J. Wright, Int. J. Clin. Pract. 2006, 60, 967-975.

[33] M. D. M. T. Cuadrado, R. F. Franco, A. M. O. Garcia, J. S. Oyarzabal, M. O. G. Rabal, World patent 131855, 2014

[34] Review on DNA targeting drugs: L. R. Hurley, Nat. Rev. Cancer 2002, 2, 188-200.

[35] D. Griffith, M. P. Morgan, C. J. Marmion, Chem. Commun. 2009, 67356737

[36] C. Liu, H. Ding, X. Li, C. P. Pallasch, L. Hong, D. Guo, Y. Chen, D. Wang, W. Wang, Y. Wang, M. T. Hemann, H. Jiang, EMBO Mol. Med 2015, 7, 438-449.

[37] W. Guerrant, V. Patil, J. C. Canzoneri, A. K. Oyelere, J. Med. Chem. 2012, 55, 1465-1477.

[38] W. Guerrant, V. Patil, J. C. Canzoneri, L.-P. Yao, R. Hood, A. K. Oyelere, Bioorg. Med. Chem. Lett. 2013, 23, 3283-3287.

[39] X. Zhang, B. Bao, X. Yu, L. Tong, Y. Luo, Q. Huang, M. Su, L. Sheng, J. Li, H. Zhu, B. Yang, X. Zhang, Y. Chen, W. Lu, Bioorg. Med. Chem. 2013, 21, 6981-6995.

[40] C.-C. Yu, S.-L. Pan, S.-W. Chao, S.-P. Liu, J.-L. Hsu, Y.-C. Yang, T.-K Li, W.-J. Huang, J.-H. Guh, Biochem. Pharmacol. 2014, 90, 320-330.

[41] S. He, G. Dong, Z. Wang, W. Chen, Y. Huang, Z. Li, Y. Jiang, N. Liu, J. Yao, Z. Miao, W. Zhang, C. Sheng, ACS Med. Chem. Lett. 2015, 6 239-243.

[42] Review on nuclear hormones: J. T. Moore, J. N. Collins, K. H. Pearce, ChemMedChem 2006, 1, 504-523.

[43] L. E. Tavera-Mendoza, T. D. Quach, B. Dabbas, J. Hudon, X. Liao, A Palijan, J. L. Gleason, J. H. White, Proc. Natl. Acad. Sci. (USA) 2008 105, 8250-8255.
[27] Review on mycophenolic acid: R. Bentley, Chem. Rev. 2000, 100 
[44] M. Lamblin, B. Dabbas, R. Spingarn, R. Mendoza-Sanchez, T.-T. Wang, B.-S. An, D. C. Huang, R. Kremer, J. H. White, J. L. Gleason, Bioorg. Med. Chem. 2010, 18, 4119-4137.

[45] J. Fischer, T.-T. Wang, D. Kaldre, N. Rochel, D. Moras, J. H. White, J. L. Gleason, Chem. Biol. 2012, 19, 963-971.

[46] G.-L. Chen, L.-H. Wang, J. Wang, K. Chen, M. Zhao, Z.-Z. Sun, S Wang, H.-L. Zheng, J.-Y. Yang, C.-F. Wu, Bioorg. Med. Chem. Lett. 2013, 23, 3891-3895

[47] H. K. Patel, M. I. Siklos, H. Abdelkarim, E. L. Mendonca, A. Vaidya, P. A. Petukhov, G. R. J. Thatcher, ChemMedChem 2014, 9, 602-613.

[48] Review on tubulin targeting drugs: D. G. I. Kingston, J. Nat. Prod. 2009, 72, 507-515.

[49] X. Zhang, J. Zhang, L. Tong, Y. Luo, M. Su, Y. Zang, J. Li, W. Lu, Y. Chen, Bioorg. Med. Chem. 2013, 21, 3240-3244.

[50] X. Zhang, Y. Kong, J. Zhang, M. Su, Y. Zhou, Y. Zang, J. Li, Y. Chen, Y. Fang, X. Zhang, W. Lu, Eur. J. Med. Chem. 2015, 95, 127-135

[51] X. Zhang, J. Zhang, M. Su, Y. Zhou, Y. Chen, J. Li, W. Lu, RSC Adv. 2014, 4, 40444-40448.

[52] Review on ERK signaling: A. A. Samatar, P. I. Poulikakos, Nat. Rev. Drug Discovery 2014, 13, 928-942.

[53] Y. Ling, X. Wang, C. Wang, C. Xu, W. Zhang, Y. Zhang, Y. Zhang, ChemMedChem 2015, 10, 971-976.

[54] Review on Wnt/ß-catenin signaling: A. Blagodatski, D. Poteryaev, V. L. Katanaev, Mol. Cell. Therapies 2014, 2, 28.

[55] J. Zhao, H. Quan, C. Xie, L. Lou, Pharmacol. Res. Perspect. 2014, 2 e00043.

[56] E. Borretto, L. Lazzarato, F. Spallotta, C. Cencioni, Y. D‘Alessandra, C. Gaetano, R. Fruttero, A. Gasco, ACS Med. Chem. Lett. 2013, 4, 994 999

[57] Review on cereblon: K. M. Kortüm, Y. X. Zhu, C. X. Shi, P. Jedlowski, A. K. Stewart, Blood Rev. 2015, 29, 329-334

[58] G. E. Winter, D. L. Buckley, J. Paulk, J. M. Roberts, A. Souza, S. DhePaganon, J. E. Bradner, Science 2015, 348, 1376-1381.

[59] J. Lu, Y. Qian, M. Altieri, H. Dong, J. Wang, K. Raina, J. Hines, J. D. Winkler, A. P. Crew, K. Coleman, C. M. Crews, Chem. Biol. 2015, 22 755-763.
[60] Review on promiscuous compounds: J. Baell, M. J. Walters, Nature 2014, 513, 481-483

[61] A. Mai, D. Cheng, M. T. Bedford, S. Valente, A. Nebbioso, A. Perrone G. Brosch, G. Sbardella, F. De Bellis, O. M. Miceli, L. Altucci, J. Med Chem. 2008, 51, 2279-2290.

[62] I. C. Pińa, J. T. Gautschi, G. Y. S. Wang, M. L. Sanders, F. J. Schmitz, D. France, S. Cornell-Kennon, L. C. Sambucetti, S. W. Remiszewski, L. B. Perez, K. W. Bair, P. Crews, J. Org. Chem. 2003, 68, 3866-3873.

[63] R. Pereira, R. Benedetti, S. Perez-Rodríguez, A. Nebbioso, J. García Rodríguez, V. Carafa, M. Stuhldreier, M. Conte, F. Rodríguez-Barrios H. G. Stunnenberg, H. Gronemeyer, L. Altucci, A. R. de Lera, J. Med Chem. 2012, 55, 9467-9491.

[64] M. G. J. Baud, T. Leiser, P. Haus, S. Samlal, A. C. Wong, R. J. Wood V. Petrucci, M. Gunaratnam, S. M. Hughes, L. Buluwela, F. Turlais, S Neidle, F.-J. Meyer-Almes, A. J. P. White, M. J. Fuchter, J. Med. Chem 2012, 55, 1731-1750.

[65] D. Rotili, S. Tomassi, M. Conte, R. Benedetti, M. Tortorici, G. Ciossani, S. Valente, B. Marrocco, D. Labella, E. Novellino, A. Mattevi, L. Altucci A. Tumber, C. Yapp, O. N. F. King, R. J. Hopkinson, A. Kawamura, C. J. Schofield, A. Mai, J. Med. Chem. 2014, 57, 42-55

[66] S. J. Atkinson, P. E. Soden, D. C. Angell, M. Bantscheff, C.-w. Chung K. A. Giblin, N. Smithers, R. C. Furze, L. Gordon, G. Drewes, I. Rioja, J. Witherington, N. J. Parr, R. K. Prinjha, Med. Chem. Commun. 2014, 5 342-351.

[67] N. R. Rose, S. S. Ng, J. Mecinovic, B. M.R. Liénard, S. H. Bello, Z. Sun, M. A. McDonough, U. Oppermann, C. J. Schofield, J. Med. Chem. 2008, 51, 7053-7056.

[68] K. Saijo, T. Katoh, H. Shimodaira, A. Oda, O. Takahashi, C. Ishioka, Cancer Sci. 2012, 103, 1994-2001.

[69] K. Saijo, J. Imamura, K. Narita, A. Oda, H. Shimodaira, T. Katoh, C. Ishioka, Cancer Sci. 2015, 106, 208-215.

[70] P. Ciceri, S. Müller, A. O’Mahony, O. Fedorov, P. Filippakopoulos, J. P. Hunt, E. A. Lasater, G. Pallares, S. Picaud, C. Wells, S. Martin, L. M. Wodicka, N. P. Shah, D. K Treiber, S. Knapp, Nat. Chem. Biol. 2014, 10, 305-313.

[71] Review on polo-like kinase: B. T. Gjertsen, P. Schöffski, Leukemia 2015, 29, 11-19. 